\title{
The Metabolism of Cyclic AMP and Glucose in Isolated Islets from Acomys Cahirinus
}

\author{
V. Grill and E. Cerasi \\ Department of Endocrinology, Karolinska Hospital, Stockholm, Sweden
}

Summary. Glucose-induced cyclic $\left({ }^{3} \mathrm{H}\right)$ AMP accumulation, insulin secretory responses and the metabolism of glucose were studied in pancreatic islets from Acomys cahirinus. $27.7 \mathrm{mmol} / 1$ of glucose stimulated neither islet cyclic $\left({ }^{3} \mathrm{H}\right)$ AMP accumulation nor insulin release during the first $5 \mathrm{~min}$ of incubation. Stimulation by glucose of cyclic $\left({ }^{3} \mathrm{H}\right)$ AMP was observed after $15 \mathrm{~min}$ of incubation and insulin release was markedly stimulated between 15 and 30 $\min$. The utilization of glucose, measured as the production of $\left({ }^{3} \mathrm{H}\right)_{2} \mathrm{O}$ from $\left(5-{ }^{3} \mathrm{H}\right)$ glucose was stimulated by glucose after $10 \mathrm{~min}$ and proceeded at an apparently linear rate during a 20 min incubation period. In incubations of $5 \mathrm{~min}$, glibenclamide, glucagon or chloromercuribenzene-p-sulphonic acid failed to stimulate islet cyclic $\left({ }^{3} \mathrm{H}\right)$ AMP accumulation. 3isobutyl-1-methylxanthine in a concentration of 1.0 $\mathrm{mmol} / 1$ was the only agent tested that elevated rapidly $(1 \mathrm{~min})$ islet cyclic $\left({ }^{3} \mathrm{H}\right)$ AMP. None of the agents tested elicited an insulin secretory response in 5 min incubations. It is concluded that 1) no gross defect is apparent in the utilization of glucose by Acomys islets, 2) the secretory derangement of the Acomys is associated with a delayed cyclic AMP response to glucose, 3) however a decreased level of cyclic AMP cannot be the sole explanation for the delayed insulin secretion in the Acomys.

Key words: Insulin secretion, isolated islets, spiny mouse (Acomys cahirinus), cyclic AMP, glucose, glibenclamide, glucagon, chloromercuribenzene-psulphonic acid, glucose utilization.

Among the diabetic and prediabetic syndromes described in animals, that of the spiny mouse (Acomys cahirinus) is of potential interest in relation to latent and maturity-onset human diabetes in man. This rodent has a tendency to develop a mild form of diabetes under laboratory conditions [1-3] and, furthermore, displays a delayed insulin response to glucose and other secretagogues [4-6], the insulin content of Acomys islets however being normal or increased [6]. In Acomys with normal blood glucose the decreased insulin release is accompanied by decreased glucose tolerance [5].

The nature of the secretory defect of the Acomys has not been elucidated. Previous observations have suggested a morphological basis for this functional deficiency, such as a reduced number of microtubules [7] or absence of autonomic annervation [2]. It has also been proposed that the delayed secretory response could result from a deficient recognition of glucose and of other stimuli as signals for insulin release [6]. Since the adenylatecyclase cyclic AMP system of the islet is believed to play an important role in the transmission of stimuli to insulin secretory mechanisms, a deficient insulin release might be the consequence of defects in this system. Alternatively, or in addition, a delayed insulin secretion could be related to metabolic defects in the beta cell. The aim of the present study was to evaluate the relation of the insulin response of the Acomys to possible changes in the islet metabolism of cyclic AMP and of glucose. To this end, cyclic AMP responses were studied with the aid of a prelabelling method, whose validity has recently been established [8]; the metabolism of glucose was assessed by measuring the glycolytic utilization of glucose.

\section{Material and Methods}

Animals. Acomys cahirinus of both sexes were obtained from the colony bred at the Institute of Clinical Biochemistry, University of Geneva, Geneva, Switzerland. The animals were brought to our 


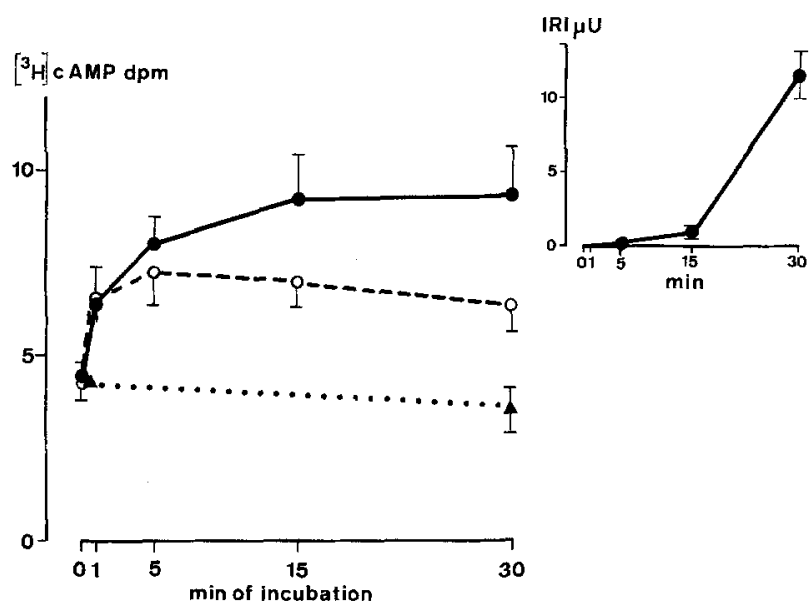

Fig. 1. Time-course of the islet cyclic $\left({ }^{3} \mathrm{H}\right)$ AMP (dpm/islet) and insulin responses ( $\mu \mathrm{U} /$ islet) to glucose and IBMX in Acomys - and --o-- denote incubations performed in duplicate with 1.0 $\mathrm{mmol} / \mathrm{l} \mathrm{IBMX}$ in the presence of 27.7 or $3.3 \mathrm{mmol} / 1$ of glucose respectively -- $A-$ - denotes incubations with $3.3 \mathrm{mmol} / 1$ of glucose without IBMX. Mean \pm SEM of 7 complete experiments. The significance of difference for the glucose effect on cyclic $\left({ }^{3} \mathrm{H}\right)$ AMP was $<0.05$ after $15 \mathrm{~min}$ of incubation. Insulin release was significantly stimulated by glucose after 15 and 30 min of incubation ( $p$ $<0.01$ or less). Insulin release in the presence of IBMX and 3.3 $\mathrm{mmol} / \mathrm{l}$ of glucose was not significant at any time-point and has been omitted from the insert. Medium cyclic $\left({ }^{3} \mathrm{H}\right)$ AMP was $3.0 \pm$ 0.4 and $1.8 \pm 0.4 \mathrm{dpm} /$ islet after $15 \mathrm{~min}$ and $4.7 \pm 0.8$ and $3.8 \pm$ $0.5 \mathrm{dpm} / \mathrm{islet}$ after $30 \mathrm{~min}$ of incubation in the presence of 27.7 and $3.3 \mathrm{mmol} / 1$ of glucose, respectively, none of these differences being significant

laboratory one month or more prior to the experiments. In Stockholm they were fed ad libitum with a commercial pelleted food (Anticimex, Stockholm) which was supplemented with a mixture of sunflower and millet seeds. The age of the Acornys at the time of sacrifice was 18-24 weeks and the weights $49.1 \pm 1.5 \mathrm{~g}$ (mean \pm SEM). Other characteristics of the Acomys were as follows (means \pm SEM, number of observations within brackets): blood glucose $5.73 \pm 0.41 \mathrm{mmol} / 1$ [25]; insulin content per isolated islet $442 \pm$ $84 \mu \mathrm{U}$ [6]; mean diameter thereof $186 \pm 10 \mu \mathrm{m}$ [3].

Isolation, Labelling with $\left({ }^{3} \mathrm{H}\right)$ Adenine, and Incubation of Islets. Pancreatic islets were isolated by the collagenase digestion method of Lacy and Kostianovsky [9], the collagenase being obtained from Worthington Biochemical Corp., Freehold, N. J., U.S.A. The incubation medium used throughout the experiments was a KrebsHenseleit-bicarbonate buffer [10] medium with $0.2 \%$ albumin $10 \mathrm{mmol} / 1$ of HEPES and - when not otherwise indicated - 3.3 $\mathrm{mmol} / 1$ of glucose. The $\mathrm{pH}$ was adjusted to 7.4. After digestion, the pancreatic sediment was washed 3 times without centrifugation. Islets were then selected under a stereo microscope and transferred to an incubation vial containing $1 \mathrm{ml}$ of buffer and 100 $\mu \mathrm{Ci}\left(2-{ }^{3} \mathrm{H}\right)$ adenine (specific activity $20,7 \mathrm{Ci} / \mathrm{mmol}$, obtained from New England Nuclear, Dreieichenhain, West Germany). They were then incubated for $60 \mathrm{~min}$ at $37^{\circ} \mathrm{C}$ with continuous gassing with $95 \% \mathrm{O}_{2}$ and $5 \% \mathrm{CO}_{2}$. The prelabelled islets were washed 4 times by brief $(20 \mathrm{sec})$ centrifugation and then selected for the final batch - type incubations in a total volume of $1.0 \mathrm{ml}$.

Assay Procedures. Cyclic $\left({ }^{3} \mathrm{H}\right)$ AMP was measured as follows: After the removal of an aliquot of the incubation medium, $100 \mu \mathrm{g}$ of cyclic AMP were added and the samples kept in a boiling water bath for 5 min. Cyclic $\left({ }^{3} \mathrm{H}\right)$ AMP was purified as previously described $[11,12]$ and the radioactivity counted by liquid scintilla- tion. The cyclic $\left({ }^{3} \mathrm{H}\right)$ AMP in the incubation medium was also determined, and the islet cyclic $\left({ }^{3} \mathrm{H}\right)$ AMP corrected for medium radioactivity remaining with the islets.

The utilization of glucose was estimated from the production of tritiated water formed from $\left(5-{ }^{3} \mathrm{H}\right)$ glucose during glycolysis. The technique described by Ashcroft et al. [13] was followed with minor modifications. Islets were preincubated as described above except for the omission of adenine. They were then transferred in batches of 10 in $20 \mu \mathrm{l}$ of buffer to glass tubes of $6 \times 30 \mathrm{~mm}$. Incubations were started by the addition of $10 \mu \mathrm{l}$ of buffer containing $400000-600000 \mathrm{cpm}$ of the radioactive glucose (The Radiochemical Centre, Amersham, Buckinghamshire, U. K.), as well as the amount of non-labelled glucose and 3-isobutyl-1methylxanthine (IBMX, Aldrich Milwaukee, Wisc., U.S.A.) necessary to yield the desired final concentrations of glucose and IBMX. After this addition, the tubes were immediately placed in larger scintillation vials which contained $0.5 \mathrm{ml}$ of $\mathrm{H}_{2} \mathrm{O}$. Incubations were carried out at $37^{\circ} \mathrm{C}$, the vials, tubes and the radioactive glucose having been prewarmed. The reactions were stopped by the addition of $10 \mu \mathrm{l}$ of $0.25 \mathrm{~mol} / \mathrm{l} \mathrm{HCl}$. The recovery of the microdiffusion process ranged from 50 to 60 per cent and was corrected for. The coefficient of variation for measurements of samples incubated identically within an experiment was $\pm 13 \%$.

Insulin was measured by a charcoal separation method of radioimmunoassay [14] using human insulin as standard. Human insulin standard was used since serial dilutions of Acomys samples react parallel to human standard [6]. For determination of the islet insulin content, 5-20 islets were extracted in acid-ethanol [15]. The blood glucose concentration was measured by a commercial glucose oxidase method (Kabi, Stockholm, Sweden). The diameters of the islets were determined using a calibrated ocular lens, two diameters being determined for each islet. Each observation represented the mean diameters of 12-16 randomly selected islets from a single experiment.

\section{Results}

Effects of IBMX on Cyclic $\left({ }^{3} H\right)$ AMP and Insulin Release. $1.0 \mathrm{mmol} / \mathrm{l}$ of IBMX in the presence of 3.3 $\mathrm{mmol} / 1$ of glucose had an immediate and sustained effect an cyclic $\left({ }^{3} \mathrm{H}\right)$ AMP which was elevated by approximately $50 \%$ from $1 \mathrm{~min}$ of incubation and onward (hatched line in Figure 1). Under these conditions IBMX did not stimulate insulin release.

\section{Effects of Glucose on Cyclic $\left({ }^{3} \mathrm{H}\right)$ AMP and Insulin} Release. The effects of a high $(27.7 \mathrm{mmol} / \mathrm{l})$ glucose concentration was tested together with IBMX since the phosphodiesterase inhibitor has been shown to augment glucose - induced cyclic AMP responses in rat islets [11]. As shown in Figure 1 glucose did not affect islet cyclic $\left({ }^{3} \mathrm{H}\right)$ AMP accumulation in 1 and 5 min of incubation when compared with the control incubations containing low glucose and IBMX (compare whole and hatched lines). As shown in the insert to Figure 1 the insulin secretory response to glucose was very small during the first $15 \mathrm{~min}$ of incubation but increased steeply after that time.

Effects of Other Agents on Cyclic $\left.{ }^{\beta} H\right)$ AMP and Insulin Release. The effects of agents known to stimulate both cyclic AMP and insulin responses in islets from other species [16-18] were tested in $5 \mathrm{~min}$ 
incubations (Table 1, upper panel). At that timepoint neither glucagon, glibenclamide nor the sulfhydryl reagent chloromercuribenzene-p-sulphonic acid (CMBS) elicited any stimulation of cyclic $\left({ }^{3} \mathrm{H}\right)$ AMP nor an insulin secretory response.

Effects of Glucose on the Production of $\left({ }^{3} \mathrm{H}\right)_{2} \mathrm{O}$ from $\left(5-{ }^{3} H\right)$ Glucose. In order to investigate whether the time-course of glucose metabolism exhibited a delay similar to that of insulin release, glucose utilization by Acomys islets was studied after 10 or $20 \mathrm{~min}$ of stimulation with the hexose (Figure 2). Insulin secretion was measured in parallel incubations (insert in Figure 2). In agreement with the results of Figure 1, insulin release was stimulated after 20 but not after $10 \mathrm{~min}$ of exposure to glucose. In contrast, an increase in glucose utilization in response to high glucose $(27.7 \mathrm{mmol} / 1)$ could be recorded already after 10 min of incubation. Furthermore, the rate of utilization was not markedly different when measurements after 10 or $20 \mathrm{~min}$ of incubation were compared.

\section{Discussion}

The present results are in good agreement with many recent studies which have established the characteristically delayed insulin response of the Acomys. Although differing in quantitative terms, this feature of the secretory profile is recognised both in vivo [4, 5] and in vitro [6] regardless of the type of stimulation used. It is seemingly independent of the age, degree of obesity or dietary state of the animal [6] and not related to the insulin content of the islet, which may be comparable to other species [6] also when the size of the islet is considered (present study). These findings may indicate that in the Acomys, there exists a fundamental defect in the mechanism of insulin release. In the age-group of Acomys used in this study this defect is associated with decreased glucose tolerance but not with hyperglycemia. [5]

The prompt increase in glucose utilization shown here seems to exclude the possibility that the delayed insulin secretion in Acomys is due to slow utilization of glucose in Acomys islets. It does not, of course, exclude the possibility that subtle abnormalities may exist in the metabolic handling of glucose in this species.

The finding that IBMX, in contrast to glucose, was able to increase promptly islet cyclic $\left({ }^{3} \mathrm{H}\right)$ AMP implies firstly that some turnover of cyclic nucleotide must occur in the islet cells also under non-stimulatory conditions. Secondly, the failure of the IBMXinduced rise in cyclic $\left({ }^{3} \mathrm{H}\right)$ AMP to stimulate an early insulin response - regardless of the prevailing glucose

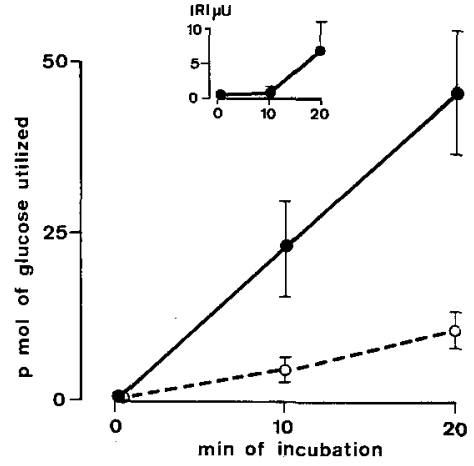

Fig. 2. Time-course of glucose utilization in Acomys islets. Islets were incubated in triplicates in batches of 10 in $\left(5-{ }^{3} \mathrm{H}\right)$ glucose, the concentration of glucose being either $27.7(-\bullet-)$ or $3.3(--0--)$ $\mathrm{mmol} / \mathrm{l}$. Results are expressed as pmol glucose utilized per islet. Insulin release was determined in parallel incubations (insert, $\mu \mathrm{U} /$ islet) performed in $0.6 \mathrm{ml}$ of an identical buffer medium except for the omission of $\left(5-{ }^{3} \mathrm{H}\right)$ glucose. Results are expressed as mean \pm SEM per islet of 4 complete experiments

Table 1. Effects of different agents on the cyclic $\left({ }^{3} \mathrm{H}\right)$ AMP accumulation in Acomys islets. $1.0 \mathrm{mmol} / 1$ of IBMX and 3.3 $\mathrm{mmol} / \mathrm{l}$ of glucose were included in all test media. Mean $\pm \mathrm{SEM}$ of 5 complete experiments. Incuabtion time $5 \mathrm{~min}$. None of the values reported were significantly different from control incubations

\begin{tabular}{lll}
\hline Additions & $\begin{array}{l}\left({ }^{3} \mathrm{H}\right) \text { cyclic AMP } \\
\text { dpm/islet }\end{array}$ & $\begin{array}{l}\text { IRI } \\
\mu \mathrm{U} / \text { islet }\end{array}$ \\
\hline none & $12.4 \pm 2.4$ & $0.0 \pm 0.2$ \\
glucagon $(5 \mu \mathrm{g} / \mathrm{ml})$ & $12.4 \pm 2.6$ & $0.1 \pm 0.3$ \\
glibenclamide $(2 \mu \mathrm{g} / \mathrm{ml})$ & $11.7 \pm 2.1$ & $0.0 \pm 0.3$ \\
CMBS $(0.1 \mathrm{mmol} / \mathrm{l})$ & $16.5 \pm 2.7$ & $0.0 \pm 0.3$
\end{tabular}

concentration - clearly shows that a mere elevation of the cyclic AMP concentration in the islets is not sufficient for correcting the delay of insulin release. Also in other investigations phosphodiesterase inhibitors, while effective as potentiators of glucoseinduced insulin release, have been unable to initiate an early insulin response in the Acomys [4]. Functional compartmentalization of cyclic AMP (where agents such as glucose but not IBMX would have access to pools associated with insulin secretion) is a theoretical but not substantiated possibility. It therefore seems unlikely that the defect of insulin secretion in Acomys is caused exclusively by a deficient islet cyclic AMP metabolism.

In contrast to the effects of IBMX, the timecourses of the glucose-induced cyclic AMP and insulin responses were qualitatively similar in the sense that stimulation was delayed for both variables in comparison with other species $[19,20]$. In islets from other species a close association between glucoseinduced effects on the two parameters has been documented under different experimental conditions $[8,11,19,21]$. Although the question of where in the 
beta-cell glucose exerts its action on cyclic AMP is unsettled, this effect does not seem to be an unspecific result of an increased ATP formation since a cyclic AMP response is not seen in other tissues [11]. Furthermore, the fact that insulin release, but not stimulation of cyclic AMP, can be inhibited by agents that affect a late step in the insulin secretory process [22] indicates that the glucose action on cyclic AMP is not secondary to the process of insulin release per se. These observations support the concept that the cyclic AMP response - aside from its precise insulinotropic role in relation to other factors - represents a valid marker of the interaction in the beta cell between glucose (or glucose metabolites) and a receptor closely linked to the insulin release mechanisms. If so, the present data suggest to us that the secretory derangement of the Acomys is due to a defect in the glucose recognition system of the beta cell.

Other secretagogues which, like glucose, in other species have associated effects on islet cyclic AMP and insulin response [16-18], were unable to stimulate the Acomys islets after a relatively short incubation $(5 \mathrm{~min})$. It should be realized that since longer incubations were not tested, the possibility has not been excluded that glucagon, glibenclamide and CMBS may be completely inactive in the Acomys. Granted this reservation, it may be hypothesized that the general mechanism of receptor activation in the Acomys islet is delayed, and in turn responsible for the modification of the kinetics of insulin release.

Acknowledgements. We are greatly indebted to Professor Albert E. Renold and Mr. Raymond Cuche, Geneva, for providing us with the Acomys. We also want to express our sincere appreciation for the expert technical assistance offered by Miss Anita Nylén and Miss Susanne Alenius. This study was supported by the Swedish Medical Research Council (grant no: B 78-19X-4540-04B and B79-19X-0540-05), the Swedish Diabetes Association, the Nordic Insulin Foundation and the Åke Wiberg Foundation.

\section{References}

1. Gonet, A. E., Stauffacher, W., Pictet, R., Mougin, J., Renold, A. E.: Obesity and diabetes mellitus with striking congenital hyperplasia of the islets of Langerhans in spiny mice (Acomys Cahirinus). Diabetologia 1, 162-171 (1965)

2. Stauffacher, W., Orci, L., Amherdt, M., Burr, I. M., Balant, L., Froesch, E. R., Renold, A. E.: Metabolic state, pancreatic insulin content and B-cell morphology of normoglycemic spiny mice (Acomys Cahirinus): indications for an impairment of insulin secretion. Diabetologia 6, 330-342 (1970)

3. Cameron, D., Stauffacher, W., Renold, A. E.: Spontaneous hyperglycemia and obesity in laboratory rodents. In: Handbook of Physiology. Section 7: Endocrinology, 1: Endocrine Pancreas. Steiner, D. F., Freinkel, N. (eds.), pp. 611-625. Washington D. C.: American Physiological Society 1972

4. Cameron, D. P., Stauffacher, W., Orci, L, Amherdt, M., Renold, A. E.: Defective immunoreactive insulin secretion in the acomys cahirinus. Diabetes 21, 1060-1071 (1972)

5. Gutzeit, A., Rabinovitch, A., Studer, P.P., Trueheart, P., Cerasi, E., Renold, A. E.: Decreased glucose tolerance and low plasma insulin responses in acomys cahirinus. Diabetologia 10, 667-70 (1974)

6. Rabinovitch, A., Gutzeit, A., Kikuchi, M., Cerasi, E., Renold, A. E.: Defective early phase insulin release in perifused isolated pancreatic islets of spiny mice (Acomys Cahirinus). Diabetologia 11, 457-465 (1975)

7. Malaisse-Lagae, F., Ravazzola, M., Amherdt, M., Gutzeit, A., Malaisse, W. J., Orci, L.: An apparent abnormality of the Bcell-microtubular system in spiny mice (Acomys Cahirinus). Diabetologia 11, 71-76 (1975)

8. Grill, V., Borglund, E., Cerasi, E.: Cyclic AMP in rat pancreatic islets: evidence for uniform labelling of precusor and product with ${ }^{3} \mathrm{H}$-adenine. Biochim. Biophys. Acta 499, 251-258 (1977)

9. Lacy, P. E., Kostianovsky, M.: Method for the isolation of intact islets of Langerhans from the rat pancreas. Diabetes 16 , 35-39 (1967)

10. Umbreit, W. W., Burris, R. H., Stauffer, J. F.: In: Manometric Techniques, p. 149. Minneapolis, Minnesota: Burgess Publish Co. 1957

11. Grill, V., Cerasi, E.: Stimulation by D-glucose of cyclic adenosine 3', 5'-monophosphate accumulation and insulin release in isolated pancreatic islets of the rat. J. Biol. Chem. 249, 4196-4201 (1974)

12. Krishna, G., Weiss, B., Brodie, B. B.: A simple sensitive method for the assay of adenyl cyclase. J. Pharmacol. Exp. Ther. 163, 379-385 (1968)

13. Ashcroft, S. J. H., Weerasinghe, L. C. C., Bassett, J.M., Randle, P.J.: The pentose cycle and insulin release in mouse pancreatic islets. Biochem. J. 126, 525-532 (1972)

14. Herbert, V., Lau, K.S., Gottlieb, C.W., Bleicher, S. J.: Coated charcoal immunoassay of insulin. J. Clin. Endocrinol. Metab. 25, 1375-1384 (1965)

15. Scott, D. A., Fisher, A. M.: The insulin and zinc content of normal and diabetic pancreas. J. Clin. Invest. 17, 725-728 (1938)

16. Hellman, B., Idahl, L-Å., Lernmark, $\AA$., Täljedal, I-B.: The pancreatic $B$-cell recognition of insulin secretagogues XII Effects of sulfhydryl reagents on cyclic AMP. Biochim. Biophys. Acta 372, 127-134 (1974)

17. Charles, M. A., Lawecki, I., Steiner, A. D., Grodsky, G. M.: Cyclic nucleotides in pancreatic islets. Tolbutamide and arginine - induced insulin release. Diabetes 25, 256-259 (1976)

18. Kuo, W-N., Hodgins, D. S., Kuo, J. F.: Regulation by various hormones and agents of adenosine-3' $5^{\prime}$-monophosphate levels in islets of Langerhans of rats. Biochem. Pharmacol. 23, 1387-1391 (1973)

19. Hellman, B., Idahl, L-Å, Lernmark, Å., Täljedal, I-B.: The pancreatic beta cell recognition of insulin secretagogues: Does cyclic AMP mediate the effect of glucose? Proc. Natl. Acad. Sci. U.S.A. 71, 3405-3409 (1974)

20. Rabinovitch, A., Grill, V., Renold, A. E., Cerasi, E.: Insulin release and cyclic AMP accumulation in response to glucose in pancreatic islets of fed and starved rats. J. Clin. Invest. 58, 1209-1216 (1976)

21. Grill, V., Cerasi, E.: Effect of hexoses and mannoheptulose on cyclic AMP and insulin secretion in rat pancreatic islets. Biochim. Biophys. Acta 437, 36-50 (1976)

22. Grill, V., Cerasi, E.: Cyclic AMP metabolism and insulin release in pancreatic islets of the rat. Effect of agents which alter microtubular function. Biochim. Biophys. Acta. 500, 385-394 (1977)

Received: October 31, 1977,

and in revised form: August 21, 1978

Dr. V. Grill

Department of Endocrinology

Karolinska Hospital

S-10401 Stockholm

Sweden 